\title{
O instituto da família e sua contextualização no ordenamento jurídico brasileiro
}

\author{
The institute of the family and its context in the Brazilian legal system \\ El instituto de la familia y su contexto en el ordenamiento jurídico brasileño
}

Recebido: 17/09/2021 | Revisado: 25/09/2021 | Aceito: 28/09/2021 | Publicado: 01/10/2021

\author{
Denise da Costa Dias Scheffer \\ ORCID: https://orcid.org/0000-0002-1755-542X \\ Universidade de Cruz Alta, Brasil \\ E-mail: dcdscheffer@gmail.com \\ Deivid Jonas Silva da Veiga \\ ORCID: https://orcid.org/0000-0002-1625-0560 \\ Universidade de Cruz Alta, Brasil \\ E-mail: deividveiga96@gmail.com \\ Dieison Prestes da Silveira \\ ORCID: https://orcid.org/0000-0002-8446-4157 \\ Universidade Federal do Paraná, Brasil \\ E-mail: dieisonprestes@gmail.com \\ Adriele Prestes da Silveira \\ ORCID: https://orcid.org/0000-0002-5157-7112 \\ Instituto Federal Farroupilha, Brasil \\ E-mail: adrieleprestesdasilveira@gmail.com \\ Joselia Cristina Siqueira da Silva \\ ORCID: https://orcid.org/0000-0003-2448-9886 \\ Universidade Federal do Paraná, Brasil \\ E-mail: jrcristinaquimica@gmail.com \\ Geovane Barbosa da Silva \\ ORCID: https://orcid.org/0000-0003-0516-7152 \\ Universidade do Noroeste do Rio Grande do Sul, Brasil \\ Universidade de Cruz Alta, Brasil \\ E-mail: bmdgeovane2019@gmail.com
}

\begin{abstract}
Resumo
O presente artigo tem por objetivo destacar aspectos doutrinários pertinentes ao instituto da família e suas nuances no ordenamento jurídico brasileiro. Serão abordados os aspectos do campo familiar previstos na legislação, ainda, a tratativa da afetividade como princípio fundamental deste instituto. A pesquisa está embasada através de referencial bibliográfico, consulta a legislação vigente, de natureza qualitativa, permeando a conceituação da temática, destacando seus aspectos conceituais. Desta forma, na finalização, perfaz a reflexão acerca do campo familiar, sua evolução oriunda do ordenamento jurídico para a coletividade.
\end{abstract}

Palavras-chave: Direito de família; Afetividade; Família.

\begin{abstract}
This article aims to highlight doctrinal aspects relevant to the institute of the family and its nuances in the Brazilian legal system. The addressed the expected aspects of the familiar field the legislation will also be addressed, as well as dealing with affectivity as a fundamental principle of this institute. The research is based on bibliographic references, consulting current legislation, of a qualitative nature, permeating the conceptualization of the theme, highlighting its conceptual aspects. In this way, in the end, he reflects on the family field, its evolution from the legal system to the collectivity.
\end{abstract}

Keywords: Family right; Affection; Family.

\section{Resumen}

Este artículo tiene como objetivo resaltar aspectos doctrinales relevantes para el instituto de la familia y sus matices en el ordenamiento jurídico brasileño. También se abordarán los aspectos esperados del campo familiar previstas en la legislación, así como la afectividad como principio fundamental de este instituto. La investigación se basa en referencias bibliográficas, consultando la legislación vigente, de carácter cualitativo, permeando la conceptualización del tema, destacando sus aspectos conceptuales. De esta forma, al final, reflexiona sobre el ámbito familiar, su evolución desde el ordenamiento jurídico a la comunidad.

Palabras clave: Derecho de familia; Afecto; Familia. 


\section{Introdução}

O ordenamento jurídico brasileiro perfaz a estrutura normativa para a aplicação das leis para a vida em sociedade, através do direito adquire sua formação jurídica para a explanação aos sujeitos acerca dos direitos e deveres na coletividade. Desta forma o direito de família está inserido no campo social da formação do grupo familiar dos sujeitos, tendo as normativas obrigacionais delineadas pelo estado e pautadas na afetividade.

O objetivo da pesquisa perfaz refletir acerca das particularidades presentes a partir da análise da evolução do instituto da família, permeado no campo da afetividade, na coletividade e seu instituído formativo na contemporaneidade, enfatizando sua evolução e seus reflexos no ordenamento jurídico brasileiro, pautados na Constituição Federal de 1988, para a formação dos sujeitos para a coletividade e compartilhamento de valores sociais éticos e morais na vida em sociedade.

O direito perfaz ferramenta essencial para a organização da vida em sociedade, é através do instituto do ordenamento jurídico, o Estado intervém para assegurar, e promover direitos, deveres e proteção aos sujeitos. Embora o Estado tenha o dever de normatizar as relações pessoais, de convívio sócia coletivo aos sujeitos, pautados no viés da liberdade individual de cada cidadão. Desta forma, deve-se observar as relações dos sujeitos para o olhar formativo afetivo para a convivência coletiva harmoniosa.

Com a evolução do tempo, aliado as constantes mudanças acerca do campo social e econômico, perfazendo as constantes mudanças para os sujeitos, aliados no entanto, aos costumes, a tradição e as culturas herdados das antigas civilizações, porém advindas do desenvolvimento para as próximas gerações, transformando as relações sociais dos sujeitos acerca da modernidade e avanços nas interações coletivas. Portanto pontuar o conceito de família permite uma reflexão variada para a sociedade atual, mas que mantém sua vinculação a princípios norteadores contemporâneos, oriundos do campo das convivências sociais dos sujeitos.

\section{Metodologia}

O caminho metodológico aplicado perfaz o referencial bibliográfico. De acordo com Gil (2008), as pesquisas bibliográficas são elaboradas a partir de material já publicado, constituído principalmente de livros, artigos de periódicos e atualmente com material disponibilizado na Internet. A pesquisa é conduzida por meio do método qualitativo, buscando evidenciar a investigação e compreensão de aspectos intrínsecos da complexidade das condutas humanas. Nesse sentido, Minayo (2013) entende que o método qualitativo ocupa níveis subjetivos de compreensão da realidade social, revendo aspectos da história, dos motivos, das crenças, das ações e valores em contraste com a atuação do sujeito perante o meio social.

\section{Resultados e Discussão}

Na contemporaneidade, tem-se a constante discussão acerca do instituto da família e suas delineações jurídicas, sociais e culturais, inspiradas tradicionalmente na concepção do poder patriarcal, da figura representativa do campo familiar, sendo elencada na Constituição Federal de 1988, situada na redação do Art. 226, a família, base da sociedade, tem especial proteção do Estado, corroborando com as palavras de Liberati (2007, p. 25), a família é, portanto, o agente socializador por excelência do ser humano. A família é identificada pela comunhão de vida, de amor e de afeto no plano da igualdade, da liberdade, da solidariedade e da responsabilidade recíproca (Lôbo, 2002, p. 138).

Desta forma, a afetividade perfaz a caracterização inerente aos sujeitos em suas relações coletivas, sendo naturalmente expressada e constitucionalmente garantida, como explica Barros (2002), o direito ao afeto é a liberdade de afeiçoar-se um indivíduo a outro. $\mathrm{O}$ afeto ou afeição constitui, pois, um direito individual: uma liberdade, que o Estado deve assegurar a cada indivíduo, sem discriminações, senão as mínimas necessárias ao bem comum de todos. 
As raízes tradicionais do instituto da família encontram-se vinculadas ao idealismo da família patriarcal, sendo constituída em sua composição pelo pai, figura central com autoridade plena, mãe e os filhos. A referida composição familiar se difundiu durante a história como a única possibilidade de instituição familiar aceita socialmente, de acordo com Alves (2007), compreende-se que o instituto da família não é considerada apenas uma instituição de ordem biológica, mas, acima de tudo, um agrupamento demarcado por características culturais e sociais.

Acerca da realidade patriarcal no campo familiar, cabe destacar as palavras de Lima (1962, p. 26), a família na sociedade destaca-se para o homem como o seu mais importante elo no relacionamento social, pois é no seio dela que ele surge, recebe a proteção indispensável para a continuidade da vida e se prepara para os embates que o futuro the reserva em termos de subsistência.

Desta forma, as interações entre os membros familiares eram sobretudo as mesmas, sendo o homem o provedor e o protetor dos demais membros, com posicionamento firmado no machismo e no autoritarismo, sobrando desta forma, a mulher, a função de cumprir tarefas domésticas, com total submissão junto aos filhos. Consagrando-se assim um direito essencial de todos, crianças, adolescentes, adultos e idosos, ter uma família. Esse direito é personalíssimo, intransferível, inalienável e imprescritível (Liberati, 2007, p. 25).

Assim enfatiza Madaleno (2018, p. 34):

[...] A mulher era totalmente subordinada à autoridade marital e podia ser repudiada por ato unilateral do marido. $\mathrm{O}$ pater exercia a sua autoridade sobre todos os seus descendentes não emancipados, sobre a sua esposa e as mulheres casadas com manus com os seus descendentes. A família era, então, simultaneamente, uma unidade econômica, religiosa, política e jurisdicional. $\mathrm{O}$ ascendente comum vivo mais velho era, ao mesmo tempo, chefe político, sacerdote e juiz.

Estes preceitos, aos poucos foram desconstruídos, em vista das constantes mudanças da sociedade, o que permitiu um convívio familiar mais democrático. Como fruto desta evolução social, foi promulgada em 1948 a Declaração Universal dos Direitos Humanos, que definiu família em seu Artigo 16, como elemento natural e fundamental da sociedade e tem direito à proteção desta e do Estado, sendo de sublime importância a formulação de leis que corroborem uma construção familiar regulada na igualdade entre os membros e não mais no rígido autoritarismo patriarcal.

Ademais, constata-se que a noção de família, inflexível e rodeada por tabus, abstém-se aos poucos de inúmeros estigmas e se expande a fim de contemplar as reivindicações sociais decorrentes da expansão e das diversidades de arranjos familiares. Desta forma, conforme a sociedade amadurece e evolui, as condutas sociais também se transformam, levando a mudanças pontuais não só na configuração social, mas ainda no âmbito jurídico, nas palavras de Gagliano (2013, p. 52) a família, hoje, tem a função de permitir, em uma visão filosófica-eudemonista, a cada um dos seus membros, a realização dos seus projetos pessoais de vida.

Inicialmente, o primeiro Código Civil Brasileiro (1916), disciplinou como primordial, no que diz respeito aos direitos de família, a proteção do patrimônio e dos interesses do homem, deixando as demais demandas como os direitos das mulheres em segundo plano. Alicerçado pelo ideal patriarcal, o referido ordenamento civil contava com artigos que deixavam de maneira nítida a sua finalidade. Nesta perspectiva, declara Barreto (2013, p. 209):

[...] Àquela época, a família patriarcal posicionava-se como coluna central da legislação e prova disso foi a indissolubilidade do casamento, como também a capacidade relativa da mulher. O artigo 233 do Código Civil de 1916 designava o marido como único chefe da sociedade conjugal. Além disso, à mulher era atribuída somente a função de colaboradora dos encargos familiares, consoante artigo 240 do mesmo diploma legal. 
A imprescindibilidade de readequar a compreensão acerca da concepção de família expandiu-se para longe do contexto social, sucedendo em mudanças legislativas, visto que os novos arranjos familiares careciam de um respaldo jurídico. Porém a discriminação não sucedia apenas entre as atribuições do homem e da mulher, sucedia também quando o tema era concernente aos filhos, não havendo amparo legal a filhos concebidos fora do matrimônio, que ficavam em um verdadeiro vácuo legislativo no que refere-se a garantias e direitos, tal qual ocorria com os filhos adotivos.

Nesta linha, Barreto (2013, p. 209) menciona que havia notória distinção entre os filhos, diferenciando-os em grau de direito, em legítimos e ilegítimos, naturais e adotivos, estando a origem da sua filiação devidamente registrada no assento do nascimento. Ademais, Barreto (2013, p. 210) também menciona que a respeito dos bens, quando o adotante tivesse filhos legítimos, não recairia os efeitos da sucessão hereditária sobre os filhos adotados, privilegiando desta forma, os legítimos em prol dos adotados.

A Constituição Federal de 1988, consagrou-se como um marco no direito de família, ao garantir igualdade entre os membros da unidade familiar, bem como a dignidade acerca dos seus direitos, dando ainda maior cobertura ao reconhecimento de novos arranjos familiares fora dos padrões então estabelecidos pelo matrimônio. Em vista dos padrões conservadores identificados no ordenamento jurídico anterior, diversas pessoas encontravam-se na margem do idealismo familiar, compondo uniões familiares que não se enquadravam aos padrões jurídicos e sociais até então vigentes.

Assim, seguindo o disposto na Constituição Federal de 1988, através do Artigo 226, inúmeros direitos concernentes ao instituto da família, verificando-se uma transformação jurídica ao extrair da Magna Carta a convicção que a família é a essência no qual o sujeito desenvolve-se com total primazia a pessoa humana. Pode-se afirmar então que, a Constituição Federal de 1988 apresentou um sentido mais igualitário a concepção de família, para os sujeitos, visto que cada sujeito apresenta a sua bagagem (Silveira; Silveira; Bassan; Silva; Scheffer, 2021)

Neste sentido, Dias (2016, p. 57), afirma que em vista dos novos valores estabelecidos pela Constituição Federal de 1988, sobreveio a universalização e consequentemente uma humanização do direito das famílias, provocando modificação nos padrões sociais e jurídicos, verificando-se um amparo mais adequado aos direitos e garantias dos indivíduos. De acordo com Scheffer (2021), a narrativa constitucional na formação dos sujeitos de direitos e deveres, perfaz a construção no campo social dos valores éticos e morais, em prol da efetiva consolidação da garantia prática da dignidade da pessoa, respeitando as relações interpessoais nas diretrizes coletivas de cidadania aos sujeitos para a vida em sociedade. Portanto, conceituando o instituto da família, cumpra-se mencionar Dias (2009, p. 55):

A família identifica-se pela comunhão de vida, de amor, de afeto no plano da igualdade, da liberdade, da solidariedade e da responsabilidade recíproca. No momento em que o formato hierárquico da família cedeu à sua democratização, em que as relações são muito mais de igualdade e de respeito mútuo, e o traço fundamental é a lealdade, não mais existem razões morais, religiosas, políticas, físicas ou naturais que justifiquem a excessiva e indevida ingerência do Estado na vida das pessoas.

Importante destacar que outra notória transformação sobreveio na dissociação da concepção de família a tradicional ramificação matrimonial, havendo o reconhecimento de organizações familiares distintas, com o estabelecimento da igualdade em direitos entre homens e mulheres, além do mais percebe-se o fim da discriminação entre filhos, sejam eles legítimos, ilegítimos, ou mesmo adotados, todos foram agraciados pela Constituição Federal a gozarem de iguais direitos e garantias, favorecendo assim um processo libertador e emancipatório para as (con)vivências sociais (Silveira; Lorenzetti, 2021).

Portanto, firmou-se assim um recomeço para o Direito de Família, com uma nova nuance acerca dos direitos, restando claro a evolução do instituto familiar, dado a presença de novas concepções de família com interações características, culminando em verdadeiras adaptações jurídicas em prol das transformações sociais. Nas palavras de Nóvoa (1991, p. 5), estar o sujeito em 
constante formação implica em investimento pessoal, um trabalho livre e criativo sobre os percursos e os projetos próprios, com vistas à construção de uma identidade [...].

\section{Conclusão}

O direito perfaz constante transformação acerca das vivências em sociedade, consolidado por meio das normativas das relações dos sujeitos, sendo ramificado desta forma para as relações familiares. Sabe-se que a entidade familiar, interligada a partir da afetividade e não somente aos liames biológicos, formam seus grupos coletivos entre os sujeitos, pautados na convivência.

A família, instituto pautado em princípios básicos e normatizados acerca da igualdade, da solidariedade e responsabilidade dos sujeitos, perfaz a comunhão de vida em sociedade, do amor e do afeto. Portanto, a função primordial da família é caracterizada na realização pessoal em relação à afetividade e à dignidade humana. Já a antiga concepção de família, preferencialmente procracional assumiu caráter secundário.

Desta forma, a pesquisa realizada acerca da temática proposta profere a realização do presente artigo científico, tem-se ainda o cumprimento objetivado a partir da reflexão proposta para discussão no campo familiar, embasado na afetividade e seus aspectos doutrinários para o instituto da família, e suas nuances no ordenamento jurídico brasileiro, promovendo o viés reflexivo e ramificado a novas pesquisas para o engrandecimento da temática a para abertura de novas discussões e pesquisas para o campo científico.

\section{Referências}

Alves, L. B. M. (2007). A função social da família. Revista Brasileira de Direito de Família. Porto Alegre, IBDFAM/Síntese, n. 39.

Brasil (1916). Código Civil Brasileiro. http://www.planalto.gov.br/ccivil_03/leis/L3071.htm.

Brasil (1988). Constituição da República Federativa do Brasil. In: Diário Oficial da República Federativa do Brasil, Brasília, DF.

Barreto, L. S. (2013). Evolução histórica e legislativa da família. In: Escola da Magistratura do Estado do Rio de Janeiro. Curso 10 anos do Código Civil: aplicação, acertos, desacertos e novos rumos. Rio de Janeiro: EMERJ, v. 1, p. 205-214. https://www.emerj.tjrj.jus.br/serieaperfeicoamentodemagistrados/paginas/series/13/volumeI/10anosdocodigocivil.pdf.

Barros, S. R. de (2002). O direito ao afeto. Instituto Brasileiro de Direito de Família. Recuperado de: http://www.ibdfam.org. br/?artigos\&artigo=50

Declaração Universal dos Direitos Humanos (1948). Assembleia Geral das Nações Unidas em Paris. https://www2.senado.leg.br/bdsf/bitstream/handle/id/508144/000992124.pdf. Acesso em: 25/09/2021.

Dias, M. B. (2009). Manual de direito das famílias. 5. ed. São Paulo: Revista dos Tribunais.

Dias, M. B. (2016). Manual de Direito das Famílias. 4 ed. São Paulo: Revista dos Tribunais.

Gagliano, P. S.; Pamplona Filho, R. P. (2013). Novo curso de direito civil: direito de família - As Famílias em Perspectiva Constitucional. São Paulo: Saraiva.

Gil, A. C. (2008). Como elaborar projetos de pesquisas. São Paulo: Atlas.

Liberati, W. D. (2007). Direito da criança e do adolescente. 2. ed. São Paulo: Rideel.

Lima, A. A. (1962). A família no mundo moderno. Rio de Janeiro: Agir Editora.

Lobo, P. L. N. (2002). Entidades familiares constitucionalizadas: pra além do numerus clausus. Belo Horizonte: Del Rey.

Madaleno, R. (2018). Direito de família. 8. ed., Rev., Atual. e Ampl, Rio de Janeiro: Forense.

Minayo, M. C. de S. (Org.). (2013). Pesquisa social: teoria, método e criatividade. (32a ed.), Vozes. (Coleção Temas Sociais).

Nóvoa, A. (1991). A formação contínua de professores: realidades e perspectivas: Universidade de Aveiro, Portugal.

Scheffer, D. da C. D. (2021). Didática da formação de professores sobre a abordagem dos direitos humanos pelo educador como formador do cidadão. Research, Society and Development, v. 10, n. 12, p. 1-7. 
Research, Society and Development, v. 10, n. 12, e555101220736, 2021 (CC BY 4.0) | ISSN 2525-3409 | DOI: http://dx.doi.org/10.33448/rsd-v10i12.20736

Silveira, D. P.; Lorenzetti. L.; Scheffer, D. C. D; Golle, D. P. (2021). Diálogos sobre educação ambiental com escolares: um enfoque na educação ambiental crítica. Research, Society and Development, V. 10, n. 3, p. 1-8.

Silveira, D. P. da \& Lorenzetti, L. (2021). Estado da arte sobre a educação ambiental crítica no Encontro Pesquisa em Educação Ambiental. Praxis \& Saber, v. 12 , n. 28 , p. $1-15$.

Silveira, A. P. da; Silveira, D. P. da. Bassan, J. S.; Silva, J. C. S. da; Scheffer, D. da C. D.; Souza, V. S. (2021). A etapa de observação e suas contribuições no campo da educação: uma análise na formação de professores. Research Society and Development. v. 10, n. 4, p. 1-8. 